24 Delacollette, C. and Barutwanayo, M. (1993) Mortalite et morbidite aux jeunes ages dans une region a paludisme hyperendemique stable, commune de Nyanza Lac, Imbo Sud, Burundi. Bulletin de la Société de Pathologie Exotique 86, 1-7

25 Barnish, G. et al. (1993) The epidemiology of malaria in southern Sierra Leone. Parasitologia $35,1-4$

26 Snow, R.W. et al. (1994) The role of the district hospital in child survival at the Kenyan coast. African J. Health Sci. 1, 71-75

27 Binka, F.N. et al. (1996) Impact of permethrinimpregnated bed nets on child mortality in Kassena-Nakana district, Ghana: a randomised controlled trial. Trop. Med. Int. Health. 1, 147-154

28 Government of Tanzania (1997) Policy implications of adult morbidity and mortality: end of Phase 1 report. Ministry of Health, Dar es Salaam, Republic of Tanzania.

29 Premji, Z. et al. (1997) Community based studies on childhood mortality in a malaria holoendemic area on the Tanzanian coast. Acta Tropica 63, 101-109

30 Salum, F.M. et al. (1994) Mortality of under fives in a rural area of holoendemic malaria transmission. Acta Tropica 58, 29-34
31 Craig, M.H. et al. (1999) African climatic model of malaria transmission based on monthly rainfall and temperature. Parasitol Today 15, 105-111.

32 Ewbank, D.C. and Gribble, J.N. (1993) Effect of Health Programs on child mortality in sub-Saharan Africa. National Academy Press, Washington DC, USA. p. 191.

33 Hill, A. (1992) Trends in childhood mortality in sub-Saharan mainland Africa. In Mortality and Society in sub-Saharan Africa (Van de Walle, E. et al., eds) pp. 10-31, Clarendon Press

34 Castro-Leal, F. et al. (2000) Public spending on health care in Africa: do the poor benefit? Bull. WHO 78, 66-74

35 Snow, R.W. et al. (1992) Childhood deaths in Africa: Uses and limitations of verbal autopsies. Lancet 340, 351-356

36 League of Nations (1936) Malaria under African conditions. Q. Bull. Health Organ. League of Nations 5, 134-137

37 Colbourne, M.J. (1966). Malaria in Africa. Oxford University Press, pp. 29-49

38 Sachs, J. (1999) Helping the World's poorest. The Economist, 14 August, pp. 17-20

39 World Health Organisation (2000) The Abuja declaration on Roll Back Malaria in Africa by the African heads of State and Government, $25^{\text {th }}$ April
2000, Abuja, Nigeria. Statement prepared by RBM, World Health Organisation, Geneva

40 Litsios, S. (1998) Arnoldo Gabaldon's independent path for malaria control and public health in the Tropics: a lost 'paradigm' for WHO. Parassitologia 40, 231-238

41 Packard, R.M. (1998) 'No other logical choice': Global malaria eradication and the politics of international health in the post-war era. Parassitologia 40, 217-229

42 Foster, S. (1995) Treatment of malaria outside formal health services. J. Trop. Med. Hyg. 98, 29-34

43 Creese,A. (1991) User charges for health care: a review of recent experience. Health Policy and Planning 6, 309-319

44 Mouchet, J.et al. (1998) Evolution of malaria in Africa for the past 40 years: impact of climatic and human factors. J. Am. Mosquito Control Assoc. $14,121-130$

45 Greenberg, A.E. et al. (1989) Hospital-based surveillance of malaria-related paediatric morbidity and mortality in Kinshasa, Zaire. Bull. WHO 67, 189-196

46 Shanks, G.D. et al. (2000) Changing patterns of clinical malaria since 1965 among a tea estate population located in the Kenyan highlands. Trans. R. Soc. Trop. Med. Hyg. 94, 253-255

\title{
Parasites that cause problems in Malaysia: soil-transmitted helminths and malaria parasites
}

\author{
Balbir Singh and J anet Cox-Singh
}

\begin{abstract}
Malaysia is a developing country with a range of parasitic infections. Indeed, soil-transmitted helminths and malaria parasites continue to have a significant impact on public health in Malaysia. In this article, the prevalence and distribution of these parasites, the problems associated with parasitic infections, the control measures taken to deal with these parasites and implications for the future will be discussed.
\end{abstract}

Malaya, occupying a strategic position in South East Asia, has played a historically important role in the study of parasitic diseases in the tropics. The Institute for Medical Research (Kuala Lampur, Malaysia), which celebrated its centenary last year, carried out most of the pioneering work on tropical

BalbirSingh* $J$ anet Cox-Singh Faculty of Medicine and Health Sciences,

Universiti Malaysia Sarawak, 94300 Kota Samarahan, Sarawak Malaysia.

*e-mail:

bsingh@fhs.unimas.my diseases, particularly on malaria and filariasis (http://www.imr.gov.my). The modern Malaysian Federation, comprising Peninsular Malaysia (formerly Malaya), and the Malaysian Borneo States of Sabah and Sarawak, was formed in 1963 and has maintained the tradition in research and the control of parasitic diseases (Table 1). The Malaysian population of $\sim 22$ million (http://www.statistics. gov.my) occupies diverse environmental niche areas and, although migration to cities is common, a significant proportion of the population remains in remote rural areas where parasitic infections are prevalent.

\section{Soil-transmitted helminths}

Ascaris lumbricoides, Trichuris trichiura and hookworms are the most common intestinal parasitic infections of medical importance in Malaysia. However, it is difficult to estimate with certainty the current overall incidence of infection with soiltransmitted helminths (STHs) among the Malaysian population. The last large-scale survey of STHs was undertaken in 1991 and involved 9863 samples from 43 squatter communities around the capital, Kuala Lumpur ${ }^{1}$. The results of this survey, comprising individuals from all age groups, indicated an overall prevalence of STH infection in $58 \%$ of the population (T. trichiura, $49 \%$; A. lumbricoides, $33 \%$; and hookworm, $6 \%$ ) and did not differ significantly from results obtained in a large-scale survey 